\title{
Revolution 4.0 and its implications for consumer behaviour
}

\author{
Wojciech Giza, Barbara Wilk
}

\begin{abstract}
A B S T R A C T
Objective: The objective of the article is to demonstrate how the achievements of Revolution 4.0 enable the modification of consumers' decision-making process by means of profiling algorithms. We indicate their potential impact - for example manifested in micro-targeting, price discrimination, and filter bubbles - and conclude with a description of the radicalization of views.

Research Design \& Methods: The article represents a theoretical study supported by reference to empirical data, the purpose of which is to determine the scale of the impact of IT sector companies on the economy.

Findings: Information Technology tools, available mainly thanks to the achievements of revolution 4.0, allow users to modify the content of information at the level of an individual consumer, thus determining their decision-making process. This may entail a new phenomenon of the individualization of mass consumption.

Implications \& Recommendations: The benefits of profiling algorithms largely contribute to the improvement of market efficiencies. Nevertheless, the accompanying threats should be clearly articulated and noticed by policymakers. High-tech enterprises, on the other hand, should assume responsibility for the fair and transparent use of profiling algorithms. Consumer awareness of the use of this technology should also be raised.

Contribution \& Value Added: The article constitutes an original analysis of the approach related to the history of economic theory and the analysis of the most recent events and developments of the current fourth industrial revolution. The text examines and shows a holistic approach to the concept of "rationality" from the beginnings of economics as a science until today, along with factors that influence its perception.

$\begin{array}{ll}\text { Article type: } & \text { conceptual article } \\ \text { Keywords: } & \text { revolution 4.0; digital revolution; 4th industrial revolution; rationality; consumer behaviour } \\ \text { JEL codes: } & \text { O33, D11, M30 }\end{array}$

$\begin{array}{lll}\text { Received: } 9 \text { May } 2021 & \text { Revised: } 8 \text { July } 2021 & \text { Accepted: } 10 \text { July } 2021\end{array}$
\end{abstract}

\section{Suggested citation:}

Giza, W. \& Wilk, B. (2021). Revolution 4.0 and its implications for consumer behaviour. Entrepreneurial Business and Economics Review, 9(4), 195-206. https://doi.org/10.15678/EBER.2021.090412

\section{INTRODUCTION}

The article aims to show the impact of the exogenous factor - Revolution 4.0 - on the perception of economic rationality and the possible consequences of implementing new digital technologies to shape consumer preferences. The article interprets the technical achievements of Revolution 4.0 as a factor modifying our perception of consumer rationality, which is the main assumption enabling us to explain the behaviour of market game participants. ${ }^{1}$ Using the demand theory, a rational and sovereign consumer determines indifference curves that form the basis on which individual demand curves are calculated. The shape of indifference curves reflects a consumer's preferences in line with postulates of rational behaviour. This method of reasoning constitutes the essence of neoclassical economics.

In the 1950s and 1960s, Herbert Alexander Simon $(1955 ; 1956)$ analysed how information deficit affects the rationality of decisions, which challenged the interpretation on which the neoclassical theory of economy is based. This coincided with the third industrial revolution, closely connected with development of information technology and the use of computers.

\footnotetext{
${ }^{1}$ We adopted assumptions that limit considerations only to the rationality of a consumer, whose origins should be sought in the neoclassical theory of economics.
} 
This article presents the analysis of the influence exerted by computing technologies on how entities make decision. In order to accomplish this goal, we recall the legacy of Charles Babbage, the mathematician and engineer who designed the Analytical Engine, commonly believed to be the first computer (Babbage, 1973; 2009). The switch from Babbage's Analytical Engine to contemporary digital computers has increased production capacities of contemporary economies, but also activated a series of various processes.

Comparing the evolution in how rationality is perceived in economics and in times of technological transformations, we put forward the following research questions:

RQ1: How has the development of information technology affected the perception of rationality among economists?

RQ2: What possibilities of influencing consumer behaviour were created by the development of technologies in the era of Revolution 4.0??

The novelty of this article lies in combining the approach dominant in modern economics with the consideration of the exogenous factors that cause profound changes in the perception of economic processes. Furthermore, we underline the relationship between industrial revolutions and the evolution of economic thought. The applied research method refers to methodological holism, which we find valuable in the determination of the effects of Revolution 4.0. The holistic approach allows us to limit the so-called fragmentation of contemporary economics presented by Roncaglia (2019).

This article is structured as follows. First, we review the literature on consumer rationality and technological change. Next, we present the development of the concept of rationality in the context of structural changes in economies, which consist in the transition from a society of mass production to a society of mass consumption. Finally, we determine new possibilities of influencing consumer behaviour through tools developed during Revolution 4.0, with reference to the achievements of the modern economy.

\section{RESEARCH METHODOLOGY}

The article is a theoretical study supported with references to empirical data, aimed at determining the strength of influence exerted by IT companies on economies. It is a conceptual article, whose research approach relies on the descriptive-analytical method. Our database consists of articles, monographs, and online resources that enabled the combination of the perspectives on the development of economic thought with the current state of knowledge about economic activity conditions in the context of Revolution 4.0. In the research process, we referred to publications from the mid-twentieth century by a Nobel laureate in economics, Herbert Simon (1978), from whose works stems the contemporary understanding of consumer rationality. The literature study combined with widely discussed changes resulting from the implementation of new digital technologies prompted us to recognize technological change as the basic exogenous factor that determines our way of interpreting consumer rationality.

The above method allowed us to interpret the relation between neoclassical understanding of consumer rationality - prevalent in current microeconomics - and its modification within bounded rationality proposed by Simon. Technological changes were selected as variables that modify our perception of rationality on the grounds of theories of economics. We analysed the process in which new technologies influence consumer behaviour in order to present how the achievements of Revolution 4.0 mostly affect the demand side of economies. In order to present the technological development process, we employed the narration typical of economic history. The arguments seek to prove the thesis that IT tools available thanks to Revolution 4.0 allow us to modify the contents of information at the level of an individual consumer, thus determining their decision-making process. This may point to a new phenomenon, namely the individualization of mass consumption. 


\section{LITERATURE REVIEW AND THEORY DEVELOPMENT}

In presenting the evolution of the concept of bounded rationality, we refer to the classical works of Simon $(1947 ; 1955 ; 1956 ; 1978)$, and their contemporary interpretations developed as part of the international business approach by Verbeke and Greidanus (2009) and Kotlar and Sieger (2018). Assuming that the key exogenous factor influencing how we interpret consumer rationality is technological development that enables the increase in computing power, we refer to the works of Moore $(1965 ; 1975)$ and Babbage (1973 [1837]; 2009 [1832]). Contemporary interpretations of Babbage's heritage are presented in the works of Wilkes (1977), Bromley (1982), Green (2005), Ozgur (2014), and Dasgupta (2014). Babbage's pioneering achievements paved the way for Revolution 4.0 presented in a broader social and economic context by Schwab (2017). The changes happening today under the influence of Revolution 4.0 are analysed by such authors as Borgesius (2015), Susskind and Susskind, (2015), Ezrachi and Stucke (2016), Wagner and Eldenmuller (2018), Wang and Kosinski (2018), Sieja and Wach (2019), Śledziewska and Włoch (2020), Rymarczyk (2020), and Křenková, Rieser, and Sato (2021).

\section{Historical Perspective on the Change in the Perception of 'Rationality'}

Contemporary economics has its roots in the Enlightenment era - an era that considered the mind the main tool for learning reality. Enlightenment thinkers rejected dogmatism and institutionalized authority, contrasting them with the scientific cognition method. They also aimed at depriving scientific discourse of arguments that refer to divine authority, which can be easily noticeable in the research approach adopted by the founding father of economics: Adam Smith. ${ }^{2}$ The central place of economics is occupied by the subject who aims at maximizing the goal function by applying rational economic calculation. However, the term 'calculation' evokes another tradition closely related to science, in which the growth of computation power has modified our perception of the decision-making process. The first scientist to identify the benefits resulting from increasing computation power and to relate them to economics was the British mathematician and designer Charles Babbage (1791-1871). He designed a difference engine, which allowed its users to calculate values of polynomial functions, and then the Analytical Engine, a direct forerunner of contemporary computers (Wilkes, 1977; Bromley, 1982; Dasgupta, 2014). The model of an analogue difference engine was developed in the 1820s, whereas the idea of an analogue analytical engine originated in the $1830 \mathrm{~s}^{3}$ It was the time when the first industrial revolution was ending and scientific inventions paved the way for the second industrial revolution, which brought about mass production.

Babbage, who was a brilliant mathematician, believed that it was absolutely necessary to find practical applications for his inventions. ${ }^{4} \mathrm{His}$ scientific interests included astronomy, philosophy, engineering, and economics. Ozgur recognizes Babbage's legacy to be an important part of contemporary microeconomics (Ozgur, 2014). In 1832, Babbage presented his views on the modification of production processes in manufactures in his work titled On the Economy of Machinery and Manufactures (Babbage 2009).

Comparing scientific approaches of Babbage and $\mathrm{H}$. Simon, we must emphasize that these thinkers did not focus on a narrowly defined single issue but sought possibilities of applying their ideas in various areas of science. The theory of bounded rationality that originated in the 1950s emerged from reflections on the analysis of a decision-making process in public administration. Simon presented his

\footnotetext{
2 In the methodological treaty by Adam Smith, History of Astronomy (1795), we find the concept of "the invisible hand of Jupiter." In Smith's later works we only find the term the invisible hand. The evolution of Smith's views shows that he wanted to remove the reference to divine authority from his scientific considerations and replace it with motivation of an individual in making economic decisions.

${ }^{3}$ A simplified model of the Difference Engine was presented by Babbage in 1822. It won recognition among members of the Astronomical Society, which helped him obtain funding for building a full-scale version of the Engine. However, the machine was not finished during Babbage's life. In 1837, he presented the description of how the Analytical Engine works (Babbage,1837; Green, 2005).

4 In 1828-1839, Babbage was the head of the most prestigious department of mathematics in the UK (Lucasian Professor of Mathematics in Cambridge). Other heads of this department include such outstanding figures as Isaac Newton 1669-1702 or Stephen Hawking 1979-2009 (Dasgupta, 2014, p. 10).
} 
views on this topic in Administrative Behaviour: A Study of Decision-Making Processes in Administrative Organization (1947). One of the key issues analysed in this book was the rationality of a decision in the context of effective management. Such interpretation of rationality differs from the one developed in neoclassical economics, in which a consumer's rationality is defined on the basis of a set of preference axioms. These include completeness, transitivity, continuity, convexity, and homogeneity. ${ }^{5}$ Developing the concept of bounded rationality (Simon, 1955; 1956; 1978), H. Simon was much more sceptical than his predecessors as far as rationality of a managing individual was concerned. His scepticism stemmed both from the limited set of information possessed by an individual initiating a decision-making process and from one's capacity to process this data. It all accounts for the fact that a managing person aims at arriving at a satisfactory rather than an optimal solution.

The development of computers in the 1950s and 1960s enabled their users to gather huge amounts of data and to process them more effectively. In this way, Babbage's idea of an analytical engine combined with the bounded rationality model postulated by Simon to become a tool that allowed to modify the behaviour of consumers of not only economic goods but also political ideas. The above processes were revealed on a large scale in the period known as Revolution 4.0, when the computer became the basic medium of social interactions and a tool steering other appliances used in everyday life. However, before that happened, the second industrial revolution brought about the phenomenon of mass production, encouraging producers to seek methods of shaping the buying preferences of their customers.

\section{From Mass Production to Mass Customization}

Industrial revolutions were possible thanks to technological progress, which facilitated profound transformations in production processes (on the supply side of economy). In the technical dimension, the first revolution of 1760-1840 brought a breakthrough in weaving and metallurgy industries, setting machines in motion with energy generated by the steam engine. Its most significant effect in social and economic spheres could be the emergence of a society no longer bound by customs and traditions but by market relations. Within such a social order, economic success allowed its authors to gain promotion in social hierarchy and improvement in the quality of their lives. The second revolution enabled the use of new energy sources, such as electricity and the combustion engine. It was also the time when the chemical industry developed. Transport was no longer exclusively based on railway, as the world witnessed the invention of the car and the airplane. Another invention - the telephone - accounted for a much quicker flow of information, while the development of cinematography created new means of artistic expression, becoming a powerful tool for shaping tastes and opinions of whole societies. By creating mass production, the second industrial revolution also created a mass consumption society. Before this happened, however, significant changes had been implemented in the production organization sphere, best seen in the example of the Ford factory.

In the Ford factory, the key role was played by new production methods that reduced costs per vehicle. As a result, the American car industry product, Ford $\mathrm{T}$, became available to a moderately wealthy American family. Changes in the production process resulting from the introduction of the assembly line in the Ford factory in Detroit drew the attention of economists to economies of scale. They concerned the supply side and enabled a reduction of average costs of production. The strategy of enterprises to increase the scale of production resulted in monopolisation and price fixing. In response to the growing monopolisation of industry, in 1890, the USA Congress passed the Sherman Antitrust Act, which was supposed to block the negative consequences of the process.

The economies of scale became an effective way to reduce production costs. However, they also generated the risk of releasing long series of products that would not attract the interest of consumers, thus resulting in substantial loss. Mass products are more homogenous than products manufactured by nineteenth-century craftsmen in their workshops. Thus, it was important that they met the de-

\footnotetext{
${ }^{5}$ The axiomatic presentation of consumer preferences in economics may be treated as an attempt at the methodological unification of economics and physics. The postulate of axiomatization of physics was formulated by Hilbert at the International Congress of Mathematicians in Paris in 1900.
} 
mands of consumers with various tastes. To reduce the risk, companies tried to tailor consumer preferences to the products they manufactured. They started advertising their products to arouse consumer desire to have specific products. The pioneer of marketing was the chairman of A\&F Pears, Thomas James Barratt (1841-1914). The promotion of the brand of soap his company produced earned him the title of the father of modern advertising (Coates, 1908, pp. 107-115; Petit, 2014). There also appeared theoretical studies on advertising, such as Henry Sampson's study published in 1874, which presented the significance of advertising from a historical perspective (Sampson, 1874).

The methods used back then to influence potential customers were not complicated. Their main goal was to unify consumer preferences by creating a fashion for a specific product. In the second half of the nineteenth century, visual means were the dominant channel through which potential consumers were to be influenced. These included posters and illustrations in news articles. This is how Barratt advertised his products. Once cinematography became popular, the marketing message was reinforced by film stars, whom all viewers, regardless of their social status, wanted to imitate. ${ }^{6}$

If we compare the means used to shape consumer preferences available in the nineteenth and twentieth centuries and those modern companies possess, we can see a major quantitative and qualitative difference. Big search engine and social media companies extensively use techniques for researching and modifying the preferences of millions of consumers worldwide. However, this would not be possible without advanced algorithms tracking every movement of a potential client in the world wide web. Ford's famous saying that you can choose any colour you like as long as it is black has long lost its meaning. Now, even though corporations do their business on a mass scale, their offering is tailored to consumer needs. This process is accompanied by a phenomenon consisting in the fact that disconnection from the web inevitably leads to social exclusion. In fact, apart from the Internet, there are no alternative communication channels or products to maintain intensive relations and contacts with the world. Therefore, companies like Apple or Microsoft are the medium that we use to communicate with others - like it or not - and in doing so, we provide those companies with huge amounts of data. These data are probably one of the most valuable assets that give competitive advantage over others. Hardware and software companies offer products that enable companies to process such data on an unprecedented scale. This way, they can effectively create what Galbraith a representative of institutional economics - called the dependence effect. ${ }^{7}$ According to this concept, needs do not reflect the autonomous preferences of consumers, but they are created by advertisements and a number of social engineering tools used by producers to trigger new needs. By doing so, entrepreneurs create demand for the products they make. The dependence effect was formulated by Galbraith exactly at the time when the third industrial revolution began. Its symbol was the computer, which enabled its users to process more and more complicated databases.

\section{Characteristics of the Fourth Industrial Revolution}

The transformations of the end of the twentieth century and the beginning of the twenty-first century that we are witnessing have a huge impact on our reality, economic processes, and the forces shaping the basic dependencies in the economy. Schwab $(2016, p$. 3) lists three main characteristics of the industrial revolution: (1) velocity (the pace of changes that we observe is exponential rather than linear), (2) breadth and depth (the complexity of and relationships between technologies change the entire economic, business, and social paradigm, even who we are as individuals), (3) systems impact (involves transformation of the entire system, both within and across entities).

The nonlinear, exponential pace of transformations related to the development of the Information and Communication Technologies (ICT) sector, is associated with the so-called Moore's law. In 1965 Gordon Moore predicted that approximately every two years the number of transistors in a dense integrated circuit doubles (Moore, 1965, 1975), therefore the computing power of appliances based on such circuits

\footnotetext{
${ }^{6}$ The first TV advertisement is believed to be the twenty-something-seconds-long advertisement of Bulov watches broadcast on $1^{\text {st }}$ July 1941 before the baseball game of Brooklyn Dodgers and Philadelphia Phillies.

7 The term "dependence effect" was used as the title of the eleventh chapter of the book The Affluent Society (Galbraith, 1958, pp. 119-125).
} 
will also double, thus increasing their capabilities. Despite negative predictions of its critics, who argued that the law would only work a few years, we can observe that it is still valid. This process translates directly into velocity of the present transformations, changing the economy instantaneously.

Susskind and Susskind $(2015$, p. 155) define four areas associated with the development of the ICT industry that have (and will have) a huge impact on the further development of the digital sector:

1. Exponential growth in information technology.

The development of the ICT industry is associated with Moore's Law. In 1965 - three years before he co-founded Intel, the world's largest supplier of integrated circuits and microprocessors - Gordon Moore predicted that more or less every two years the number of transistors per integrated circuit would double, which, avoiding technical jargon, simply means that the computing performance of devices based on such circuits would also double. His critics expected that this law would not work longer than for a couple of years. However, observations show that it is still valid. Exponential growth is extremely powerful, and its implications are hard to predict. In the first 50 years following the introduction of computers, the cost of their computing performance was reduced more than 10 billion times. Constant development in this area is accompanied by complementary aspects, such as the increasing throughput of networks and capacity of hard disc drives, which has been growing at a similar pace.

2. Increasingly capable machines.

This is one of the most important contemporary changes in the labour market. It is associated with the thesis that more and more tasks that used to require human labour are now done more effectively, better, faster, and cheaper by machines. Moreover, this is no longer true only for routine tasks. The main reasons are such trends as the use of Big Data pools (which enables us to analyse past experiences and patterns and prognosticate), the development of systems that apparently require human intelligence, progress in robotics, the development of affective computing, namely computers that understand and can express emotions.

3. Increasingly pervasive devices.

Devices are becoming physically smaller, and their prices are dropping significantly, which enables a large part of the society to own various kinds of computers. Some estimate that currently there are more than 6 billion cell phone subscriptions, and more than 2 billion people own smart phones with Internet access (the latter number is expected to double). The internet of things is developing rapidly, and computer systems and the Internet are installed in everyday objects, such as fridges, kettles, lighting, thermostats, and even flowerpots. Moreover, we wear intelligent devices, such as watches that track the activity of our bodies.

4. Increasingly connected humans.

Since the Internet is becoming increasingly available and many processes have moved to the digital world, people do more and more things online: we communicate, research, socialise, share, build communities, co-operate, crowd-source, compete, and trade. This enables the development of business models and platforms that would not yield such economies of scale and would not perform their functions if their users were not connected to worldwide network.

\section{DISCUSSION}

Even though we cannot predict the direction in which new technologies will develop, let alone their impact on the socioeconomic environment, we should observe dominant trends and try to draw conclusions from them. Noticing certain trends will at least partly enable a dialogue about the institutional environment, including the direction societies and economies should follow.

One of the main characteristics of contemporary changes is also the growing role of enterprises in the technology sector. Big tech companies - often referred to as GAFAM (an acronym made of the first letters of: Google, Apple, Facebook, Amazon, Microsoft) - are currently not only providers of the latest ICT solutions but also very important players in international relations. Data on the market value of the largest Internet companies and their growing revenues are presented in Figures 1-2. 


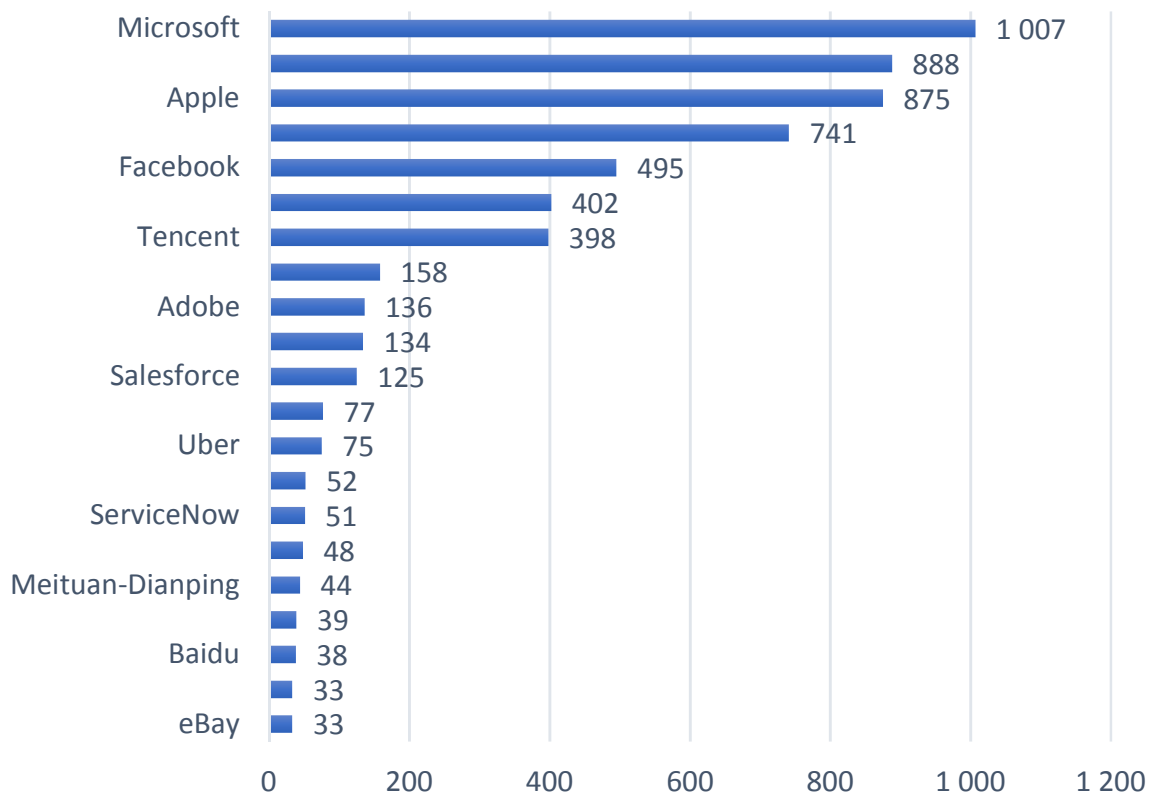

Figure 1. Market value of the world largest Internet companies (June 2019, data in billions of USD) Source: Statista (2020d).

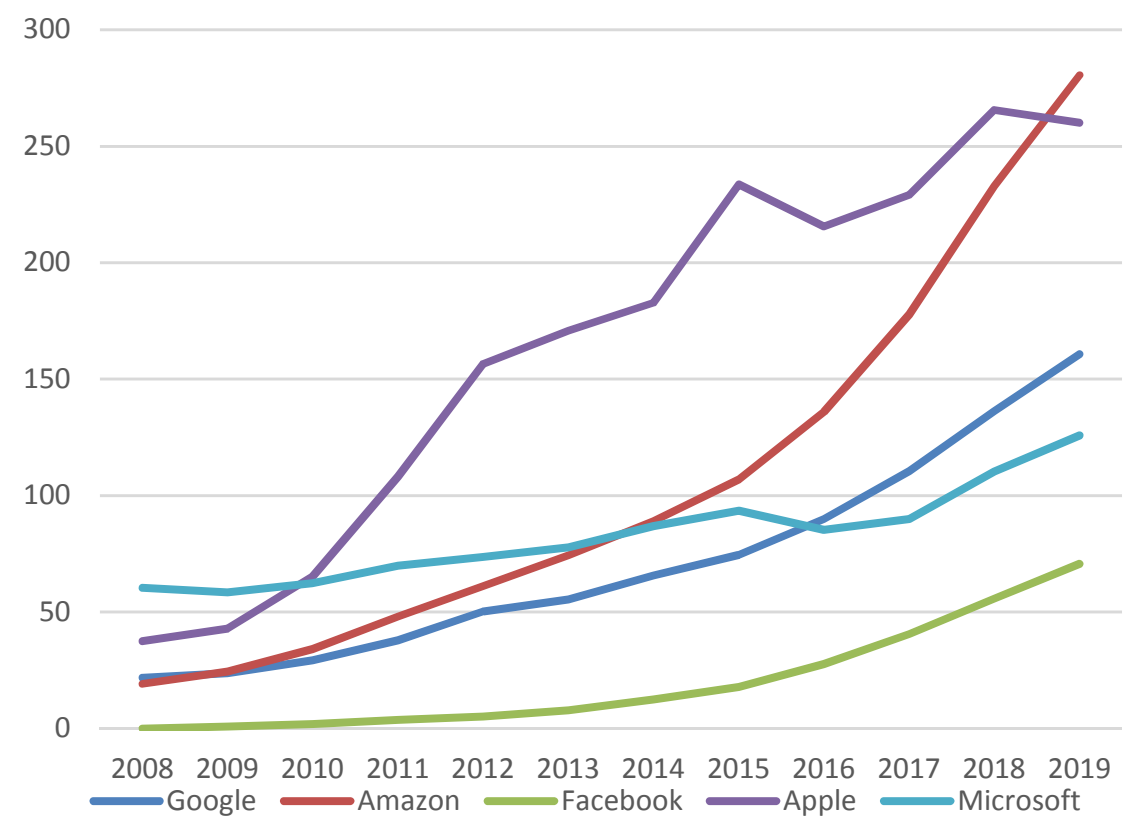

Figure 2. Revenues of Google (Alphabet), Amazon, Facebook, Apple, Microsoft (2008-2019 data in billions of USD)

Source: Statista (2020a; 2020b; 2020c; 2020e).

The main arguments against the business model of the above companies and their growing impact on the economic and political situation concern such issues as the use of private information for commercial purposes, excessive lobbying, the lack of responsibility for the social consequences of their actions, and attempts to monitor and control consumer and citizen behaviour (Fontanel \& Sushcheva, 2019). The last of these issues in particular has become the topic of heated political and social debates, 
following the Cambridge Analytica scandal in which data of nearly 50 million people were used for the purpose of profiling political campaigns (especially the US presidential campaign in 2016).

The data that users leave online are often sensitive and concern such issues as ethnic origin, sexual orientation, religious denomination, or political preferences. The Cambridge Analytica scandal aptly illustrates how sensitive data of millions of users were used to create voter profiles and to employ behavioural marketing (Śledziewska \& Włoch 2020, p. 127). During the 2016 presidential election campaign in the USA, Robert Mercer, an American billionaire, supported a project (with USD 15 million) aimed at developing a tool analysing psychophysical parameters of users. Based on this project, the head of the team of marketing experts created appropriate content and media messages, which were then placed in social media and television. They were to influence their recipients' preferences during the election campaign.

In addition to the political and social aspects of the analysed problem, there is an economic dimension that translates directly to shaping the demand structure of the market and consumer preferences. Although, as Mazurek (2006) suggests, the idea of the Internet market is the same as the idea of the market defined in traditional economy - with prices determined by both demand and supply for a given product - the former has certain specific features which, if used by big tech companies, may give competitive advantage over other entities. The development of big data together with advanced algorithms supported by artificial intelligence creates new transaction tools, previously unavailable to companies. Data analysis enables enterprises to profile their consumers, which significantly disturbs the symmetry of information. As a result, companies very often know about consumers more than the latter know about themselves. An example is an algorithm developed by scientists from Stanford and Cambridge. All it needs is ten "likes" to know about a person more than their colleague from work, 70 - more than their friends, and 150 - more than their family members. Notably, a Facebook user on average has given 227 likes. Another example is facial image analysis. Based on 35,326 facial images, an algorithm has learned (with $81 \%$ accuracy for men and $71 \%$ accuracy for women) to identify whether a person is heterosexual or homosexual. The accuracy increases to $91 \%$ and $83 \%$, respectively, if five images of the same person are analysed (Wang \& Kosiński, 2018).

Below we present the areas that reflect potential negative effects of the growing importance of technology in daily life. Let us note that apart from the phenomena listed below, there also is a number of positive aspects of digitization. However, the aim of this essay is to draw attention to the increasing advancement of available technologies and profiling algorithms, which leads to changes on the demand side of economy and in shaping consumer preferences.

Powerful knowledge acquired through the use of appropriate data processing is transformed by large technology companies into marketing microstrategies (and also ideological and political strategies, as revealed the Cambridge Analytica scandal), which shape preferences in a way to enable companies to achieve expected (and predicted) results. With this type of tools, companies may personalise the content they produce and profile their users e.g. as "high spenders" (Borgesius, 2015). This is done by analysing the purchase history, based on the basis which one can conclude that a person likes buying expensive products. Within such targeted business-to-consumer (B2C) transactions, Wagner and Eidenmuller (2018) identify three areas that cause serious concern. These include:

- price discrimination,

- exploitation of behavioural biases of consumers,

- using microtargeted advertisements to control preferences in certain ways.

Noteworthy, there are three different types of price discrimination. The first one concerns different pricing based on individual preferences of consumers. The second type refers to different pricing depending on the quantity (e.g. discounts for bulk purchases). The third one involves offering different prices to different consumer groups (e.g. students, old-age pensioners). Price discrimination is nothing new, but digital tools and big data analysis enable its application on an unprecedented scale, especially the first type of price discrimination (Ezrachi \& Stucke, 2016).

If price discrimination is to be effective, it must meet three requirements: (1) the company must possess a competitive advantage to be able to set its price above marginal cost, (2) the seller must be 
able to differentiate clients to tailor prices appropriately, and finally, (3) the reselling of products must be rather impractical and costly (Varian 1989). In the case of the digital market and internet sales (combined with the dominant position of major players in the market), the above conditions seem relatively easy to be fulfilled. Price personalization is based on the information the company obtains from various sources, such as (Borgesius, 2015):

- voluntary and conscious provision of such information by the client (e.g. when creating an account on a particular Internet platform),

- data left by users after visiting a website (IP address and cookies),

- data obtained from third parties concerning consumer behaviour online and visited websites.

The last two sources of information are mainly used in assessing a particular user's readiness to pay a specific price for the product; e.g. a person residing in a wealthy district is more inclined to pay more for a product than a person from poorer neighbourhood. Obviously, this strategy is not flawless. Many people surf the net e.g. in search of a Ferrari car, even though they cannot afford it.

According to researchers, microtargeted advertisements aimed at steering user preferences online negatively affect individuals, who are trapped in a narrower life. They believe that the choice of an individualised price system should be up to the consumer and that the consumer should be able to withdraw from it at any time. Behavioural biases may also lead users into ineffective transactions and prevent them from experimenting, i.e. doing things that do not match the model of a given user. On the other hand, the use of this type of algorithms may help increase consumer satisfaction and loyalty, while a personalised offer may help prevent decision-making paralysis caused by the availability of too many options, which in turn will increase effectiveness both in the micro (transaction) and macro (social) scale (Wagner \& Eidenmuller, 2018). Nonetheless, price discrimination (especially its first degree) makes consumers feel unfairly treated by service and product providers. This may make them try remaining anonymous to companies and has resulted in the emergence of a growing number of tools such as Tor or Anonabox. However, according to Wagner and Eidenmuller (2018), such preventive measures are insufficient, and the regulator's role in the process should be more pronounced. However, this is a major challenge as technologies such as big data or artificial intelligence develop at a very high pace and in a direction that is not quite clear or predictable. Thus, measures aimed at controlling the direction of the further development of innovations and preventing potential threats are important. The most radical regulation would be to put a complete ban on price personalisation that is not justified by cost differences. Less radical solutions would e.g. include increasing consumer awareness so that they make more informed and rational decisions.

Concerning the development of preferences, we should note that measures associated with presenting goods and services purchased by a similar type of user is vital for the idea of choice in itself. This is because they limit the availability of goods and services and offer only selected access to reality. Exposure to constantly personalised information (filter bubble) may influence such important issues as political preferences (leading to views radicalisation) since the stream of news available to a given user becomes very limited. In Choosing Not to Choose, Sunstein (2014, p. 44) writes that there is a difference between active and passive choice: "If people have made an active choice, they are more likely to become invested in it, and in a sense to like it. These same effects may not occur when the choice has been made passively and by default." Algorithms that provide adjusted information, consistent with user preferences, discourage a creative approach, limit diversity, and promote a passive attitude to reality.

\section{CONCLUSIONS}

Contemporary science and engineering enable us to understand and modify the surrounding world in categories rooted in the idea of rationality. This rational model of science became particularly important in the period of the Enlightenment when economics emerged as an independent branch of science. The central part in the new science was occupied by a rational homo oeconomicus, who aimed at maximizing own benefits. Along with economics came new technical inventions which allowed to 
increase the productivity of human work. The machine became a tool facilitating the accomplishment of goals set by people. New inventions, whose practical application in industry marked consecutive industrial revolutions, have brought tremendous changes in the supply side of the economic sphere. The above changes have been both admired and feared, as the machine, and the computer in particular, has been replacing human labour. Fears of machines date back to the times of the first industrial revolution. They were analysed by D. Ricardo, who considered the problem of technological unemployment. ${ }^{8}$ Contemporary reflections on the Industrial Revolution 4.0 are also accompanied by fears of losing jobs which will be performed by robots and artificial intelligence. What seems of particular importance in Revolution 4.0 - although it is rather neglected by economists who analyse the effects of these changes - is the impact of new technologies on the demand side of economy. When at the beginning of the twentieth century, Ford's assembly line made mass production possible, consumer tastes and preferences were shaped through advertisements addressed at masses. Modern information technologies, the Internet, and profiling algorithms used by big corporations not only to reach potential consumers but also to modify their behaviour far exceed the economic sphere. These activities also concern political elections (as with the Cambridge Analytica scandal) and an area that has been treated as a sphere of individual beliefs. The world in which the Analytical Engine invented by Charles Babbage has adopted the shape of highly efficient computers is characterized by an advanced instrumental treatment of IT tools and our understanding of rationality. New technologies reinforce activities that can be explained in rational categories as well as those which arouse irrational desires of particular individuals and social groups. The main limitation of our study is the generalization of outcomes resulting from the approach referred to as a conceptual study. Our conclusions obtained based on the literature review requires further verification and empirical research. As part of further research directions, we find it important to determine the potential impact of Revolution 4.0 not only on the real economy but also on the perception of this process by the public and regulatory actions taken by individual states. In this regard, it is also crucial to determine whether possible market failures resulting from the implementation of new technologies can be limited by state actions.

\section{REFERENCES}

Babbage, C. (1837[1973]). On the Mathematical Powers of the Calculating Engine. In B. Randell (Ed.), The Origins of Digital Computers, Springer-Verlag Berlin.

Babbage, C. (1832[2009]). On the Economy of Machinery and Manufactures. New York: Cambridge University Press.

Borgesius, Z. (2015). Online Price Discrimination and Data Protection Law. Working Paper for the Amsterdam Privacy Conference 2015, Institute for Information Law Research Paper No. 2015-02.

Bromley, A.G. (1982). Charles Babbage's Analytical Engine, 1838. Annals of the History of Computing, 4(3), 196-217.

Dasgupta, S. (2014). It Began with Babbage: The Genesis of Computer Science. Oxford [England]: Oxford University Press.

Ezrachi, A., \& Stucke, M. (2016). The rise of behavioral discrimination. European Competition Law Review, 37(12), 485-492. http://dx.doi.org/10.2139/ssrn.2830206

Fontanel, \& J., Sushcheva, N. (2019). La puissance des GAFAM: réalités, apports et dangers. Annuaire français de relations internationales, Paris: La Documentation française, volume $X X, 198-222$.

Green, C.D. (2005). Was Babbage' Analytical Engine Intended to be a Mechanical Model of the Mind? History of Psychology, 8(1), 35-45. https://doi.org/10.1037/1093-4510.8.1.35

Kotlar, J. \& Sieger, P. (2018). Bounded Rationality and Bounded Reliability: A Study of Nonfamily Managers' Entrepreneurial Behavior in Family Firms. Entrepreneurship Theory and Practice, 43(1), 251-273. https://doi.org/10.1177/1042258718796085

Křenková, E., Rieser, K., \& Sato, A. (2021). How software robots can facilitate the procurement process? A case study of Siemens in the Czech Republic. Entrepreneurial Business and Economics Review, 9(3), 191-203. https://doi.org/10.15678/EBER.2021.09031

\footnotetext{
8 Ricardo presented his views on the relationship between machines and unemployment in the third edition of On the Principles
} of Political Economy and Taxation published in 1821 (Ricardo, 2001). He analysed these issues in chapter 31 titled "On Machinery." 
Mazurek, G. (2006). Rynek internetowy a uwarunkowania rynku doskonale konkurencyjnego, In G. Sobczyk (Ed.) Zachowania podmiotów na rynku w warunkach konkurencji. Aspekty Marketingowe. Lublin: UMCS.

Moore, G. (1965). Cramming More Components onto Integrated Circuits. Electronics, 38(8), 114-117.

Moore, G. (1975). Progress in Digital Integrated Electronics. IEEE Solid-State Circuits Society Newsletter, 11(3), 36-37.

Ozgur, M.E. (2014). Babbage's Legacy: The Origins of Microeconomics in “On the Economy of Machinery and Manufactures". Scottish Journal of Political Economy, 61(3), 322-339. https://doi.org/10.1111/sjpe.12047

Ricardo, D. (2001 [1821]). On the Principles of Political Economy and Taxation. Kitchener, Ontario: Batoche Books.

Roncaglia, A. (2019). The Age of Fragmentation. A History of Contemporary Economic Thought. Cambridge UK: Cambridge University Press.

Rymarczyk, J. (2020). Technologies, Opportunities and Challenges of the Industrial Revolution 4.0: Theoretical Considerations. Entrepreneurial Business and Economics Review, 8(1), 185-198. https://doi.org/10.15678/EBER.2020.080110

Schwab, K. (2017). The Fourth Industrial Revolution. New York: Penguin Random House.

Sieja, M., \& Wach, K. (2019). The Use of Evolutionary Algorithms for Optimization in the Modern Entrepreneurial Economy: Interdisciplinary Perspective. Entrepreneurial Business and Economics Review, 7(4), 117-130. https://doi.org/10.15678/EBER.2019.070407

Simon, H. (1947). Administrative behavior: A Study of Decision ?making Processes in Administrative, New York: The Macmillan Company.

Simon, H. (1955). A Behavioral Model of Rational Choice, The Quarterly Journal of Economics, 69(1), 99-118. https://doi.org/10.2307/1884852

Simon, H. (1956). Dynamic Programming Under Uncertainty with a Quadratic Criterion Function, Econometrica, 24(1), 74-81. https://doi.org/10.2307/1905261

Simon, H. (1978). Rationality as Process and as Product of Thought. The American Economic Review, 68(2), 1-16.

Śledziewska, K., \& Włoch, R. (2020). Gospodarka cyfrowa. Jak nowe technologie zmieniaja świat. Wydawnictwa Uniwersytetu Warszawskiego, Warszawa.

Smith, A. (1795). The Principles which Lead and Direct Philosophical Enquiries; Illustrated by the History of Astronomy. In D. Stewart (Ed.) Essays on Philosophical Subjects. Dublin: The Online Library of Liberty.

Statista (2020a). Annual net revenue of Amazon, Retrieved from https://www.statista.com/statistics/266282/annual-net-revenue-of-amazoncom/ on 17 June 2020.

Statista (2020b). Comparison of Apple, Google, Alphabet, and Microsoft from 2008 to 2019, Retrieved from https://www.statista.com/statistics/234529/comparison-of-apple-and-google-revenues/ on 17 June 2020.

Statista (2020c). Facebook's annual revenue from 2009 to 2019, Retrieved from https://www.statista.com/statistics/268604/annual-revenue-of-facebook/ on 17 June 2020.

Statista (2020d). Market value of the largest internet companies worldwide, Retrieved from https://www.statista.com/statistics/277483/market-value-of-the-largest-internet-companies-worldwide/ on 17 June 2020.

Statista (2020e). Microsoft's global revenue since 2002, Retrieved from https://www.statista.com/statistics/267805/microsofts-global-revenue-since-2002/ on 17 June 2020.

Sunstein, C.R. (2014). Choosing Not to Choose. Duke Law Journal, 64(1), 1-52.

Susskind, R., \& Susskind, D. (2015). The future of professions. How technology will transform the work of human experts? Oxford University Press.

Varian, H. (1989). Price Discrimination. Handbook of Industrial Organization, volume 1, 597-654.

Verbeke, A. \& Greidanus, N.S. (2009). The End of the Opportunism vs Trust Debate: Bounded Reliability as a New Envelope Concept in Research on MNE governance. Journal of International Business Studies, 40(9), 1471-1495.

Wagner, G., \& Eidenmuller, H. (2018). Down by Algorithms? Siphoning Rents, Exploiting Biases, and Shaping Preferences: Regulating the Dark Side of Personalized Transactions. The University of Chicago Law Review, 86(2), 581-609.

Wang Y., \& Kosinski M. (2018). Deep neural networks are more accurate than humans at detecting sexual orientation from facial images. Journal of Personality and Social Psychology, 114(2), 246-257. https://doi.org/10.1037/pspa0000098 
Wilkes, M.V. (1977). Babbage as a Computer Pioneer. Historia Mathematica, 4(4), 415-440.

https://doi.org/10.1016/0315-0860(77)90079-9

\section{Authors}

The contribution share of authors is equal and amounted to $50 \%$ for each of them.

\section{Wojciech Giza}

Associate Professor at the Department of Microeconomics at the Cracow University of Economics (Poland). His scientific research interests include the development of economics as a science and the analysis of theoretical and methodological foundations of neoclassical economics, especially the issues of market failure. As far as institutional economics is concerned, he conducts research on comparative analysis of economic systems with particular emphasis on ordoliberalism and social market economy.

Correspondence to: prof. UEK dr hab. Wojciech Giza, Cracow University of Economics, Department of Microeconomics, ul. Rakowicka 27, 31-510 Kraków, Poland, e-mail: gizaw@uek.krakow.pl

ORCID $\odot$ http://orcid.org/0000-0002-6773-1372

\section{Barbara Wilk (born Barbara Sztokfisz)}

Chief Strategy Analyst at EXATEL - Polish telecommunication company, since 2021. Previously, researcher at the Kosciuszko Institute, Polish non-governmental think tank and research institute (2017-2021), where she was Chief Editor of the 'European Cybersecurity Journal'. She graduated in International Economics and European Studies at the Cracow University of Economics and French Language and Literature at the Jagiellonian University. She is fourth-year PhD candidate at the Cracow University of Economics with the specialisation in economics of technological change. Her research interests include digital transformation, blockchain technology, and the impact of artificial intelligence on the labour market.

Correspondence to: Mgr Barbara Wilk, Cracow University of Economics, Department of Microeconomics, ul. Rakowicka 27, 31-510 Kraków, Poland, e-mail: barbara.sztokfisz@gmail.com

ORCID $\odot$ http://orcid.org/0000-0002-5615-7571

\section{Acknowledgements and Financial Disclosure}

This article was written under the "Regional Excellence Initiative" project financed by the Polish Ministry of Science and Higher Education, project no. 021/RID/2018/19.

\section{Conflict of Interest}

The authors declare that the research was conducted in the absence of any commercial or financial relationships that could be construed as a potential conflict of interest.

\section{Copyright and License}

This article is published under the terms of the Creative Commons

Attribution - NoDerivs (CC BY-ND 4.0) License

http://creativecommons.org/licenses/by-nd/4.0/

Published by Cracow University of Economics - Krakow, Poland 